\title{
Alien worlds, alien laws, and the Humean conceivability argument
}

\section{Lok-Chi Chan $^{1}$ (D) | David Braddon-Mitchell ${ }^{2}$ | Andrew James Latham ${ }^{2}$}

\author{
${ }^{1}$ Department of Philosophy, National \\ Taiwan University, No. 1, Sec. 4, Roosevelt \\ Rd., Taipei City, 106, Taiwan \\ ${ }^{2}$ Department of Philosophy, The University \\ of Sydney, Quadrangle A14, Sydney, NSW \\ 2006, Australia \\ Correspondence \\ Lok-Chi Chan, Department of Philosophy, \\ National Taiwan University, No. 1, Sec. 4, \\ Roosevelt Rd., Taipei City 106, Taiwan. \\ Email: lokchan@ntu.edu.tw
}

\begin{abstract}
Monism is our name for a range of views according to which the connection between dispositions and their categorical bases is intimate and necessary, or on which there are no categorical bases at all. In contrast, Dualist views hold that the connection between dispositions and their categorical bases is distant and contingent. This paper is a defence of Monism against an influential conceivability argument in favour of Dualism. The argument suggests that the apparent possibility of causal behaviour coming apart from categorical bases is best explained by Dualism. We argue that Monism can explain the apparent possibility as well, if we take metaphysically alien laws - namely, laws whose metaphysical nature is alien to the actual world - into account.

\section{KEYWORDS}

categoricalism, dispositionalism, Humeanism, Langton, modal intuition
\end{abstract}

\section{1 | INTRODUCTION}

There is a range of views according to which the relationship between dispositions and categorical bases is especially intimate. That intimacy goes as far as identity on some views (see, for example, Heil, 2003; Martin \& Heil, 1999; Mumford, 1998; Strawson, 2008), necessary connection of some kind on others (see, for example, Oderberg, 2009), and includes views where the nature of a disposition is determined by the nature of its categorical basis (see, for example, Seager, 2009). There is also a range of views according to which there really are no bases, only primitive dispositions - or primitive powers - standing in for bases (see, for example, Bird, 2005; Shoemaker, 1980; Swoyer, 1982).

One upshot to these families of views is that the connection between behaviours and their fundamental bases - categorical bases, primitive dispositions, or primitive powers - is both intimate and necessary. After 
all, if how something is disposed to behave is identical with, or ontologically depends just on, its bases - categorical bases, primitive dispositions, or primitive powers - we would expect it to behave the same way in any world where the bases are duplicated along with the bases of anything that might be within range to interact with that thing. Connected with this view tends to be the view that the laws of nature ontologically depend just on such bases - categorical bases, primitive dispositions, or primitive powers - as opposed to being distinct entities which produce dispositions and behaviours by their interaction with categorical bases, and which, if arranged differently, could confer different patterns of disposition and behaviour to the same bases (Langton, 1998; Lewis, 1986a, 2009).

It is not an easy task to discuss these diverse families of views, each of which consists of numerous variants, in a general way. For the purposes of this paper, we will call views where dispositions are identical with or ontologically depend just on their bases - categorical bases, primitive dispositions, or primitive powers - 'Monism'. Conversely, we will use 'Dualism' to refer to the opposite family of views according to which there is a distant and contingent relation between dispositions and their categorical bases. Further, from now on whenever we use the term 'bases' in the context of Monism we are, unless otherwise specified, referring to the disjunction of categorical bases, primitive dispositions, and primitive powers. It is noteworthy in the metaphysics of dispositions that some other authors use 'monism' and 'dualism' to pick out ranges of views in a more restricted fashion than we would like (see, for example, MacLean, 2012). For instance, some 'dispositional monists' might insist that there are only dispositions or powers, and reject the view that dispositions or powers could have categorical bases. Nevertheless, as we will use the term, 'Monism' refers to a broader range of views - including views where there is an identity or dependence relation between dispositions and categorical bases. Thus 'Monism' as we use it is not the stronger view that all properties are intimately related to dispositions, just that all dispositions are intimately related to bases - categorical bases, primitive dispositions, or primitive powers. So the argument we attempt to refute in this paper targets all accounts that fall under our use of the term Monism, and we will show that it is ineffective against any version of them.

Some readers might find the labels 'Monism' and 'Dualism' (and our usage of them) unappealing or unhelpful, but nothing we say in this paper hangs on this choice. Those who dislike our use of terminology should feel free to replace them with 'necessitarianism' and 'contingentism', 'strong and weak dispositionalism' and 'strong categoricalism', 'non-combinatorialism' and 'combinatorialism', and so on, with a caveat that the usual definitions of those terms might not align perfectly with the arguments in this paper.

In this paper we will defend Monism in the metaphysics of dispositions against a prominent Conceivability Argument for Dualism. Versions of the argument have been proposed by Dualists like Rae Langton (1998, pp. 118-119, 2006, pp. 175-176) and David Lewis (1986a, p. 163), and even suggested by Monists, such as Shoemaker (1980, p. 119), Swoyer (1982, p. 210), Heil (2003, p. 94), and Strawson (2008, p. 277). These arguments depend on a broadly Humean intuition according to which it is possible that things could be intrinsically just like they are, but behave causally in ways that are different from how they behave actually. Shortly we will present one popular characterization of this argument due to Langton. Here then is the plan for the paper. In $\int 2$ we will present and describe the Conceivability Argument. Then in $\int 3$ we will outline our response to the Conceivability Argument. In $\int 4$ we will discuss an idea which our response relies on: metaphysically alien laws, namely, laws whose metaphysical nature is alien to the actual world. In $\int 5$ we will respond to what we think are the most interesting objections to our response. Finally, in 56 we will conclude.

\section{2 | THE CONCEIVABILITY ARGUMENT}

The Conceivability Argument depends on the Humean Modal Intuition. This intuition is, of course, not something that is specific to either Humean accounts of laws, nor indeed the specific thesis of Humean Supervenience. It has 
been described by many authors. Very few authors, though, offer a systematic formulation of the argument. One such formulation is provided and defended by Langton. She writes:

[T]hings could be just as they are with respect to their intrinsic properties [i.e., categorical bases], yet different with, respect to their causal powers [i.e., dispositions] - in particular, that if the laws of nature were different, things could have the same intrinsic properties, but different powers. [...] These modal intuitions rest on certain assumptions about the contingency of laws of nature, and the contingency of connections - if any - between intrinsic properties and causal powers. These modal intuitions suppose that causal powers do in a sense depend on something other than the way a thing is, in and of itself: that causal powers do depend on something else - but the something else is not simply the existence of some distinct object, but the existence of certain laws. (1998, p. 118, original emphasis) $)^{1}$

As we see it, Langton's idea is that the Humean modal intuition gives us some reason to think that no version of Monism can be true. This is because any view in the Monism family requires that the intrinsic nature of things necessitates their causal nature. Each thing must be disposed to behave in the way it actually does, in every possible world in which it exists and has the same bases. If it behaves differently in some world, while being intrinsically the same, there must be some other factor actually at play not fixed by its bases - for instance a law of nature that does not ontologically depend on bases, but which interacts with a thing's bases to produce its causal dispositions. ${ }^{2}$ Thus, if the Humean intuition that things could be the same with respect to intrinsic nature but different with respect to causal behaviour, there can be neither an intimate connection between dispositions and bases nor laws of nature that ontologically depend just on the bases of things.

\section{3 | OUR RESPONSE}

It is worth highlighting that the argumentative strategy of Langton (and other Dualists) is to point out that the falsity of Monism is an explanation of our Humean intuition. Hence it is tempting to simply reject the Conceivability Argument by pointing out that the Humean intuition is idiosyncratic, in the sense that it reflects a mere error, only shared by other Dualists - and in fact this has been the standard response by Monists (see, for example, Bird, 2007, p. 170; Heil, 2003, p. 94; Shoemaker, 1980, p. 119; Strawson, 2008, p. 277; Swoyer, 1982, p. 210). Perhaps this is right; however, to the best of our knowledge no one has actually investigated just how widespread the Humean intuition is, a lacuna in the literature that would be good to have filled. ${ }^{3}$ With this in mind, a much more powerful way to reject the argument is to assume the Humean intuition is widely held and show that Langton's explanation is not the only attractive one. There might be alternative explanations that not only explain the pervasiveness of the Humean intuition, but which are consistent with the truth of Monism as well. It is this strategy that we adopt in this paper.

\footnotetext{
${ }^{1}$ Langton uses the terms 'intrinsic properties' and 'causal powers' instead of 'categorical bases' and 'dispositions. Nevertheless, she herself makes it clear that what she calls 'intrinsic properties' and 'causal powers' are what some other philosophers call 'categorical bases' and 'dispositions' (1998, pp. 120-132, 2006, pp. 176-177), and is not making the distinction that some make between intrinsic properties and categorical bases, or between dispositions and causal powers (see, for example, Huoranszki, 2012).

${ }^{2}$ Or in Lewis' case, the unconstrained recombination of all the categorical bases in different worlds, with the laws at that world supervening on the overall recombination in the entire world (for further details, see Lewis, 1986a, 1986b).

${ }^{3}$ Another response is to deny that our intuitions are reliable. For example, conceivability is sometimes said to be an unreliable guide to possibility. For instance, the Dualist may assert that the Humean intuition means nothing to her despite the fact that she herself shares it, because she thinks that her Humean intuition is unreliable. Such an interlocutor is not the target of this paper. The targets of this paper are the majority of authors who appeal to a Humean intuition. As such, we will not even attempt to address the evidentiary status of our intuitions.
} 
One route that is consistent with this strategy involves adapting responses to conceivability arguments from other areas of philosophy, such as in philosophy of mind (Braddon-Mitchell, 2003). For instance, the Monist may well conceive of the scenario where Dualism is true about the actual world, and thereby the possibility that actual dispositions and their bases can come apart in some other worlds. But this does not mean that Dualism is actually true, nor does this render the Humean intuition inexplicably mistaken. For no one knows for sure what the actual world is like, and even an extremely confident Monist should give some credence to Dualism being true and vice versa. Put simply, from the perspective of the Monist, the Humean intuition, though mistaken, is nonetheless a serious derivation from a view to which she gives some credence, no matter how small the credence is.

However, in this paper we provide and defend a novel and more powerful line of response to the Conceivability Argument. Our thought is this. It is compatible with Monism with respect to the intimate relation between dispositions and their bases, that there is no such intimacy with respect to the relation between behaviours and their bases.

Monists suppose that the actual laws of nature ontologically depend just on the bases. This is essential to guarantee the intimate relation between dispositions and their bases. Imagine then, that some atom $A$ is $\operatorname{disposed}$ to decay at $t$ and actually does. In the actual world, let us accept that the laws of nature depend just on the bases. So, $A$ 's behaviour is determined solely by A's bases. Yet, we can still imagine that A's behaviour might have been different (the Humean intuition). How could this be? Put simply for now, because that possible world might be a world that contains some alien laws of nature!

\section{TWO KINDS OF ALIEN LAWS}

There are two kinds of alien laws of nature that might help to explain the Humean intuition: metaphysically alien laws and mere alien laws. We believe that a response to the Conceivability Argument that appeals to the former is the strongest, and will therefore focus on it, but we will illustrate both. Metaphysically alien laws are laws whose metaphysical nature (as opposed to their mere nomological content) is alien to the actual world (and perhaps any metaphysically possible world as well). If there are any such laws in a world, then some actually false metaphysical theories of laws would be true in that world. For example, the kinds of law described by Dualists like Langton would be metaphysically alien laws, if Monism is actually true; the same can be said about other kinds of laws that do not ontologically depend on bases, and that interact with bases to produce behaviours (see, for accounts of these laws by authors who hold them to describe how the actual world is, Armstrong, 1983; Broad, 1923; Carroll, 1994; Tooley, 1987; Van Cleve, 1990).

By contrast, what we call mere alien laws are laws that merely have differentnomological contents to those of their actual counterparts. For example, if the actual laws ontologically depend just on primitive powers, then nonactual laws that depend on non-actual primitive powers would count as mere alien laws. Conversely, non-actual laws that do not depend on non-actual primitive powers would not count as mere alien laws. What we call mere alien laws should not be understood merely as slight variants of the actual physical laws, such as a slightly different cosmological constant. A world contains only mere alien laws if the nomological contents of its laws differ from actuality, and the metaphysical theories of laws (like Monism, Dualism, Lewis's Humean supervenience thesis, or the recent power metaphysics) that apply to them are the same, or a subset, ${ }^{4}$ of the metaphysical theories of laws that apply to the laws in the actual world. ${ }^{5}$

\footnotetext{
${ }^{4}$ We are grateful to an anonymous referee for this useful precisification - just because a world does not have the same theories of laws true at it in virtue of having fewer kinds of laws than the actual world, is not enough to make it a metaphysically alien world.

${ }^{5}$ Hence neither kind of alien law should be understood in terms of its nomological or physical similarity to the actual laws. On the one hand, some mere alien laws might be so different from the actual laws that they might not even be describable by the language of our physical science. On the other hand, the nomological contents of some metaphysically alien laws might be similar, or even identical to, those of some actual laws.
} 
We should point out that, for our purpose, mere alien laws can be further classified into at least two possible kinds: the kind described by the Dualist framework and the kind described by the Monist framework. Dualists like Langton believe mere alien laws are what ground the Humean intuition. In Langton's view, for example, our actual laws are ontologically fundamental, independent, and interact with our bases to produce behaviours. Mere alien laws, accordingly, are laws with the same metaphysical nature as the actual laws - that is, being ontologically fundamental, independent - and with the potential to interact with the same bases to produce different behaviours. She thinks this shows that Monism is false because it cannot posit such a kind of mere alien law. However, we believe that there is much more to say here. The Monist framework can also posit mere alien laws, though of another kind: laws that ontologically depend just on alien bases - alien categorical bases, alien primitive dispositions, or alien primitive powers - and hence are not present in the actual world. Still, if Monism is right, this kind of law shares the same metaphysical nature with our actual laws: both depend just on some bases.

We have already seen how mere alien laws as described by Dualism could explain the intuition. Now, we will describe how mere alien laws as described by Monism can explain the intuition.

It seems possible that some alien bases - alien categorical bases, alien primitive dispositions, or alien primitive powers - could interact with actual properties. For example, it seems possible that actual properties could be attracted to or repelled by some alien properties in ways that are unrelated to the fundamental physical forces we know of, and thereby display non-actual patterns of behaviours. ${ }^{6}$ If these mere alien laws are even conceivable, then the Conceivability Argument is not compelling. However, making use of mere alien laws has an obvious weakness. It is simply not obvious that we are, by the lights of the Humean intuition, conceiving of the interactions between actual and alien properties, or between actual and alien things which bear the relevant properties. For instance, recall the example that some atom $A$ is disposed to decay at $t$ and actually does. The Dualist might object that when we conceive of the possibility that it did not decay, it is not in virtue of the possibility that it interacts with a nearby atom $B$ and does not decay; it simply does not decay! Namely, she might claim that only the original, actual properties or things are involved in her conceived scenario, or that no additional properties or things are involved. Either way, alien properties - or alien things that bear them - are not given any opportunity to enter the Dualist's conceived scenario. Since mere alien laws depend on alien properties, they cannot help to explain the conceived scenario. ${ }^{7}$ Instead, we will appeal to metaphysically alien laws. First, more on these laws.

By a metaphysically alien law we mean a law whose type of law-maker is alien to the actual world. So, let us suppose, for illustration, that the actual world is a Humean world. The law-makers are then patterns of distribution of locally instantiated properties and are nothing above and beyond this. Now, consider a world which is also a Humean world, but has alien properties which obey Humean supervenience, the patterns of which are lawmakers for different laws. These would still be merely alien laws in our terminology, as while there are new, alien properties in this world, the type of property - properties obeying Humean supervenience and which form patterns - is not novel.

But when we consider other kinds of accounts of laws of nature, we get a different story. Consider for example the Armstrong-Tooley account (Armstrong, 1983; Tooley, 1977). On this story, laws are contingently obtaining relations of necessitation between universals (a kind of second-order universal which, when instantiated, guarantees the necessitation of one first order universal by another). A world which contains such properties - second order universals guaranteeing such necessitation - contains an entirely different kind of lawmaker, and thus, relative to the Humean world, is a metaphysically alien law. Or to take another example, Douglas Ehring's (1997) account of laws makes them depend on the endurance of tropes. Such an account relies on quite different kinds of lawmakers

\footnotetext{
${ }^{6}$ For an objection to this prima facie possibility, see Shoemaker (1980). We take no stance on whether the prima facie possibility is correct; our argument does not depend on it.

${ }^{7}$ Recently, it has been argued by some authors that dispositionalists are committed to Platonism (see, for example, Tugby, 2013; Yates, 2017). It is therefore worth noting that an appeal to mere alien laws is not available for Monists who endorse a Platonist account of properties - since, for the Platonist the same dispositions exist in all worlds. We would like to thank an anonymous referee for highlighting this point.
} 
than the Humean story. Thus relative to a Humean world, a world with Ehring laws is has metaphysically alien laws. On an account in which laws are primitive (Carroll, 1994), then they will the alien relative to the Humean world. If they depend on other primitives: either say counterfactuals (Lange, 2004) or dispositions (Bird, 2005; Shoemaker, 1980; Swoyer, 1982) then they too will be alien relative to the Humean world. Indeed every Monist account discussed so far, if true at a world, will make that world have alien worlds relative to a Humean world.

So, containing metaphysically alien laws is a relation (just as alienness of properties is in the first place) between the actual world, and some laws in some other world. The examples above of metaphysically alien laws are all relative to an actual world conceived of as Humean.

But being a Monistic or a Dualistic world with respect to the laws is not a relational one. It is true of a world simpiciter. For example, a Humean world is a limiting case of a Dualist world. It is Dualist because what the dispositions are does not depend solely on what categorical properties there are: it also depends on their distribution. It is a limiting case because what's required in addition to what categorical properties there are, is not something substantially extra by way of lawmaking properties as you find in primitive theories, or ones like the ArmstrongTooley account.

Accounts of laws which contain local dispositions (such as the Shoemaker-Swoyer account) will be Monistic. Perhaps Ehring's account will be Monistic as well, as the laws are intimately tied to the local facts about endurance of tropes and these local facts determine distributions.

The Armstrong-Tooley account, on the other hand, is a paradigm of a nontrivially Dualistic account. For the lawmakers are entities which could exist or not, consistent with the same distribution of local categorical properties. There exists, on this account, a 'law skeptical' world, like ours in its distribution of properties, but entirely lacking laws. Perhaps, on this account, there could be no world which had the same distribution of dispositions, but if so, this is not because the laws are made by the dispositions, but because they are made by the laws. A primitivist account might also be Dualistic in this way, to the extent that it allows for the primitive laws, and thus the dispositions, to exist or not exist consistent with the same distributions of categorical properties, as appears to be the case on some readings of Tim Maudlin's (2007) account in The Metaphysics Within Physics.

The idea of metaphysically alien laws is useful in responding the conceivability argument - and is thereby the foundation of a stronger response than an appeal to mere alien laws. Return to the case of atom $A$ failing to decay at $t$. Suppose Monism is actually true, and the laws, for instance, are ontologically fundamental, irreducible, and independent entities (Broad, 1923; Carroll, 1994; Langton, 1998; Maudlin, 2007; Van Cleve, 1990). We can then note that atom $A$ does not decay at $t$ because there is a metaphysically alien law in the world that determines that it does not decay. We need not appeal to its interaction with some nearby atom $B$ to explain its failure to decay.

Of course, if Monism is actually true, then the world being conceived of is a world with metaphysically mixed laws. That is, it is a world with at least two metaphysical kinds of laws. There are a number of possibilities of how two metaphysically different kinds of laws might interact when they are governing - or are supposed to govern - the same property. Here are a few examples. First, one law may override and thereby completely mask another; the property concerned may act only in accordance with the former law. Second, the two laws may mask each other, and as a result the property concerned acts in accordance with neither of them. This in turn might allow for a third law to completely govern the property. Third, the two laws may jointly produce some aggregated effect. For example, if a particle $\mathrm{C}$ has a charge of $2 \times 10^{-19} \mathrm{C}$ under one law, and a charge of $-1 \times 10^{-19} \mathrm{C}$ under another, the particle may turn out to behave as if it has a charge of $1 \times 10^{-19} \mathrm{C}$. Which, if any, of these interactions describes the interaction between metaphysically different kinds of laws, is not important for our purposes. What is important is that all these possibilities allow for the compatibility between Monism and the Humean intuition. ${ }^{8}$

Can this convince the Dualist that the Monist understanding of mere alien laws is not the only plausible explanation of the Humean intuition? Probably not; she might insist that we could, by the lights of the Humean intuition, conceive of a world where there are only actual properties and no metaphysically alien laws, but the properties

${ }^{8}$ Chan (2018) provides another detailed discussion of another interesting example of such interactions. 
still behave otherwise. Hence, metaphysically alien laws cannot fully account for the Humean intuition. But this would be a mistake, for this objection proves too much: it is equally problematic for the Conceivability Argument and its Dualist proponents. Recall that the Dualist must appeal to the idea of alien laws to explain the Humean intuition as well: actual properties are thought to be able to behave otherwise in some other worlds because there are mere alien laws (of the kind described by Dualism) in those worlds. Not even the Dualist can make sense of how actual properties might display different (patterns of) behaviours in worlds where there are no mere alien laws. Put simply, the difference between the Monist and the Dualist here is that, if our above discussion is correct, the Monist may only appeal to metaphysically alien laws to account for the Humean intuition, while the Dualist can appeal to both mere alien and metaphysically alien laws. Importantly, both of them must appeal to some kind of alien law.

Now it should be clear why the Dualist's objection is problematic. If, we assume that the Humean intuition allows us to conceive of worlds where actual properties behave otherwise, and there are no (mere or metaphysically) alien laws, then neither Monism nor Dualism can make sense of the Humean intuition. If, however, we assume that the Humean intuition only allows us to conceive of worlds where the actual properties behave otherwise and there are no metaphysically alien laws, then of course only Dualism can make sense of intuition. Monism must be false if the intuition is correct. But it seems massively unlikely that our intuitions alone are sufficiently fine-grained to make such a precise, sophisticated metaphysical distinction like the one between mere alien and metaphysically alien laws. To the best of our knowledge we have found no author who provides such a precise description of their intuition, despite the fact the Humean intuition and the Conceivability Argument have been discussed and debated for many decades. Hence it seems warranted to infer that the distinction is no part of the widely held Humean intuition. ${ }^{9}$

\section{5 | FURTHER CONSIDERATIONS AND POSSIBLE OBJECTIONS}

We will now discuss three further objections, and by doing so further develop the argument we have presented so far.

\section{1 | Objection one}

Here is the first objection. Whereas our argument may be of use to kinds of Monism that suppose that there are categorical bases, it is not clear either how it could be of use to those that posit primitive dispositions or primitive powers, or else dispositions that are necessitated by their bases.

The worry is as follows. While it might be intelligible that categorical bases might be deprived of their powers, and be brought under control of some metaphysically alien laws, if the bases concerned are, say, primitive powers, how could they be deprived of their powers, which are just themselves? Or, how could a

\footnotetext{
'Lewisian-Humean reductionist versions of Dualism may escape the dilemma. The idea is that mere alien laws are an 'ontological free lunch'. On this view, there are in fact no 'governing' laws or powers, only arrangements of properties, and the so-called laws of nature are mere descriptions of these arrangements. Applying this view to the Humean intuition: any world that consists only of properties in the actual world, albeit a different arrangement of them, may be one that has mere alien laws for free. Hence, the Lewisian-Humean reductionist does not need to consider alien laws as an ontological addition to that world.

While Lewisian-Humean reductionism has this advantage over Monism and other versions of Dualism, we think that there are good reasons to believe it is false. Firstly, even Lewis agrees that not all scientific generalizations of the arrangements of properties are laws; but then the laws of nature would be those generalizations we grant a special nominal status in accordance with our explanatory framework. Accordingly, this model of laws is a bizarrely subjectivist one (see, for example, Dretske, 1977). Secondly, if there are ultimately only arrangements and no governance, then the very regular, repeating patterns of natural phenomena that are described and predicted by natural sciences would be mere coincidences (see, for example, Strawson, 1989). Of course, these objections are very far from conclusive. However, for our purpose here, which is to assess theories of categorical and dispositional properties in accordance with their consistency with our intuitions, this suffices. For we have very strong (albeit not Humean) intuitions that laws of nature are objective affairs discovered by natural sciences, and that the very regular, repeating patterns of natural phenomena are not mere coincidences.
} 
primitive disposition, under any circumstance, act against itself - say, moving upwards for distance $d_{1}$ when its very nature is to move downwards for distance $d_{2}$ ? The same can be said if dispositions are entailed by categorical bases: perhaps it is intelligible that the base can be deprived of its power, but surely not the entailed disposition.

Before explaining our replies to this, we should acknowledge there are numerous kinds of dispositions and we cannot hope to discuss them all here. Thus, we shall focus on the spatial motion case outlined above. We see no reason why our discussion of that case should not generalize to other kinds of dispositions.

We offer four possible solutions to this worry. The reader might take these in the spirit of alternatives. We, the authors each favour one of these solutions, but we do not agree.

\subsubsection{Solution one}

We agree that the very nature of a primitive power or disposition might be to move downwards for distance $d_{2}$. But metaphysically alien laws may allow the power or disposition to act otherwise in a two-step process. The first step is as follows. Most dispositionalists agree that a power or disposition might be prevented from manifesting if it is masked by something else. A mask does not remove the disposition it interferes with, but instead interferes with the process in which the disposition manifests (Bird, 1998). For example, an object's disposition of fragility can be masked by being covered by cotton balls, bubble-wrap and so on. It is difficult to see why a power or disposition to move downwards for distance $d_{2}$ could not be masked by a metaphysically alien law. Of course, mere masking only prevents a disposition from manifesting. It does not confer any interesting varieties of new behaviours of the kind we find in worlds conceived of by the lights of the Humean intuition. This is where the second step comes in. Most dispositionalists agree that powers or dispositions have states, such as their spatial and temporal locations. Of course these states may be inherited from properties of objects: so if an object which is fragile is located at $\mathrm{L}$, then this instance of fragility is in the state of being L-located. Again, it is difficult to see why a metaphysically alien law could not alter the state(s) of some power or disposition, its spatial location in our case, moving upwards for distance $d_{1}$, even if such a movement was not due to the intrinsic nature of the power or disposition. We shall leave the case to the dispositionalist who insists the case is otherwise. So long as a metaphysically alien law could alter the spatial and temporal location of a power or disposition, we see no reason why it cannot alter its other states, such as its temperature and charge, though this might have to be done in some more complex ways. It is for this reason that we think our discussion can generalize to other cases.

Our first possible reply is one on which the alien laws have not created any new dispositions. It is a pure masking story, according to which the dispositions remain the same, and the alien laws make things behave differently even though they are not disposed to.

\subsection{2 | Solution two}

The next possible reply is to say that, relative to a world in which Monism is true, the categorical properties (a) wholly determine the dispositions actually possessed and (b) make it necessary that those dispositions (but possibly not only those dispositions) are possessed. Thus, in a world with alien laws, the dispositions possessed in the Monist world will survive, but be masked, but that masking would happen in part due to the presence of additional dispositions. ${ }^{10}$ This would preserve the idea that there is an intimate connection between categorical properties and dispositions in a Monist world and that these properties necessitate those dispositions in every world, but reject the claim (not in any case always made) that only those dispositions are possessed by those categorical properties in very odd (by the Monist's light) worlds.

\footnotetext{
${ }^{10}$ We would like to thank an anonymous referee for alerting us to this possibility.
} 
On this story new dispositions will be possessed, but only in virtue of the alien laws. It is still true that the categorical nature entails the possession of a core set of dispositions in every world, even if they are masked and perhaps overridden by other dispositions in some worlds.

\subsubsection{Solution three}

Another approach is to think of dispositions as multi-track across worlds. The idea is that there is a single disposition to behave in way $A$ when there are no metaphysically alien laws, but in way $B$ when there are metaphysically alien laws $X$, in way $C$ when there are metaphysically alien laws $Y$, and so on and so forth. To illustrate by way of example, an atom with bases $\alpha$ only has a single disposition $\beta$ with regard to its decaying. $\beta$ is: (1) to decaying at $t$ when there are no metaphysically alien laws, (2) to never decay when there are metaphysically alien laws $X$, and (3) to decay at $t_{1}$ when there are metaphysically alien laws $Y$. (1), (2), and (3) are all features of disposition $\beta$, which is in turn necessitated by bases $\alpha$.

There are two worries associated with this response. First, it might be thought that this could lead to significant epistemological difficulties, since it makes each disposition complex and unintelligible. In order to fully grasp a disposition, we must take into account its patterns of (potential) manifestations under all laws, including all metaphysically alien ones, and this is practically impossible.

This objection is a mistake. It is not necessary to fully grasp the disposition of a thing when, for instance, doing science: all we need to know in science is its pattern of (potential) manifestations in the actual world (and worlds without metaphysically alien laws). We can simply bracket off its patterns of (potential) manifestations under metaphysically alien laws.

Second, it might be thought that this response is trivial as it means everyone turns out to believe in necessary connections between bases and their disposition. But this is not true. As we pointed out earlier, if Monism is true, then a certain class of Humean worlds is ruled out. If Monism is true, then if the categorical bases in the actual world entail certain behaviours when not interfered with, then there can be no worlds without alien overriding laws in which dispositions fail to manifest as they do actually. Thus, some folk do reject the necessary connection between bases and dispositions - namely those who believe in the possibility of a Humean world which contains the same categorical properties as the actual world (most obviously those who believe in worlds with the same categorical properties but different distributions).

\subsection{4 | Solution four}

The forth promising response was suggested by an anonymous referee. We might think of the manifestation of dispositions as not behaviour itself, but rather as a contribution to behaviour. It is a kind of inter world variant of one way of understanding ordinary dispositions. Perhaps the disposition, for instance, of the positive charge of a proton to repel another proton is not prevented from manifesting by the strong nuclear force. Rather, the disposition is in fact manifested as a contribution to total effect, to which the strong nuclear force also contributes. So, in the case we are considering, we could argue that the categorical property, or the primitive disposition, or the dispositions entailed by the categorical property, not only retains the disposition but also manifests it as a contribution to an effect to which the alien laws also make a contribution. ${ }^{11}$

At least one of these ways of proceeding will preserve the basic idea that we could believe Monism to be true of the actual world - believe that the dispositions that things actually have are (for example) identified with their categorical properties, and that therefore these dispositions are present in every world - whilst making sense of the idea that in very different worlds from how the Monist takes the actual world to be, things so disposed can behave differently.

\footnotetext{
${ }^{11}$ Though see McKitrick (2010) for an argument against this view.
} 


\section{2 | Objection two}

The next objection has two parts. The first concerns the understanding of the sense in which alien laws are taken to be possible. If we were to think of them as not being substantially or metaphysically possible at all, but merely conceptually possible (some authors use 'logically possible' to pick out this sense but that is not our practice) then the whole idea of alien laws might be thought to be unnecessary: one might just imagine that behaviour coming apart from categorical nature is conceptually, but not metaphysically, possible, and this directly explains the intuition.

But this is not our view. Our view is that, even if Monism is true, some (but not all) alien kinds of laws are possible, and metaphysically possible too.

To make this point it is important to distinguish two different sense of 'metaphysically possible'. Sometimes metaphysical possibility is just taken to be the realm of the genuinely possible (rather than merely conceptually possible given our flawed and maybe confused concepts). So, on this account of metaphysically possible, all the concrete worlds of Lewis (this is purely an example, we are not Concretists about the worlds) are metaphysically possible. ${ }^{12}$

But there is a more restrictive sense of 'metaphysically possible'. This is metaphysical possibility constrained by a similarity relation around a world. It is rather like nomological possibility: a world $W_{A}$ is nomologically possible, relative to a world $W$ iff it shares the laws of nature of $W$. It is not an absolute constraint on whether a world is genuinely possible. So, a world is nomologically possible relative to the actual world, if it shares the same laws of nature.

Metaphysical possibility in the more restrictive sense is also relative to a world. A world $W_{A}$ is metaphysically possible relative to a world $X$ iff it shares the same metaphysics as $X$. It is not any kind of absolute constraint on whether a world is possible. A world is metaphysically possible relative to the actual world, if it shares the same metaphysics. So, if the actual world is one where Monism is true, and there are no (for example) Tooley-Armstrong laws, then Tooley-Armstrong laws are not metaphysically possible in this narrow sense. But that does not mean that they are not metaphysically possible in the broader sense. Thus our account is one on which we are assuming that a degree of contingentism is true about laws of nature. This objection does not apply to the sense in which we intend alien laws to be metaphysically possible.

There is an interesting question, though, about whether our story has anything to add if we think that strict necessitarianism is true about metaphysics, and the only sense in which alien laws might be possible is a conceptual or a hyperintensional one, or a 'merely logical' one. We address this point at the end of the next section.

\section{3 | Objection three}

Having clarified the sense in which we take alien laws to be metaphysically possible, the question arises as to whether the idea of worlds with non-actual metaphysics is too idiosyncratic to be playing any role in our intuitions, and thus is not a fit explanation for our Humean intuition. One strong version of this objection would be that according to the orthodox view in metaphysics, the metaphysical nature of the actual world is not contingent, but is instead metaphysically necessary; and hence metaphysically alien laws are metaphysically impossible. The idea, then, is that our intuitions probably do not concern worlds whose metaphysical nature is very different from our own - especially, if they are in fact metaphysically impossible. Hence, our explanation of the Humean intuition which appeals to metaphysically alien laws - is inadequate.

We will suggest two lines of reply to this objection. On the one hand, the 'orthodox' necessitarian view of metaphysics is more controversial than many might think - many theoreticians disagree with it. There is

\footnotetext{
${ }^{12}$ For Lewis (and at least one of the current authors) the logically possible and the metaphysically possible worlds are the same; there is no distinction.
} 
considerable recent interest in contingentism, the view that metaphysics is contingent and there exist possible worlds that are metaphysically different from actuality. ${ }^{13}$ On the assumption that metaphysical contingentism is true, our explanation of the Humean intuition is straightforward. The Humean intuition, without being inconsistent with Monism, simply describes some other possible worlds. Further, our view is also interesting in the sense that it describes one of the consequences of contingentism. Namely, the same categorical natures may directly determine behaviours in some worlds and do it via some metaphysically different kinds of laws in other worlds.

But for our proposal to work, global contingentism about metaphysics need not be true. The contingentist is not committed to the idea that every idea in metaphysics, which is not an obvious contradiction, reflects a way a world might be. So, some accounts of laws might not be accounts of how things could be. All that is required for our story to work is that, consistent with taking the actual world to be Monist, there is at least one account which is possible according to which laws are non-local things directing the behaviour of local things and overcoming any intrinsic tendency to behave which the local things possess.

It is worth noting, too, that contingentism of this weak kind may not just be a matter of ruling out some accounts of laws as impossible. There may be relations between the different accounts, such that there are only certain copossible packages. So, consider, especially the relationship between the possibility of Monist worlds and Humean worlds. For this purpose, it is worth distinguishing two sorts of Monist world. The first says that actual properties instantiated are identical, or entail, or otherwise necessitate certain dispositions. The other says that all possible categorical properties are necessarily connected to some disposition or other. Of course if any world is a Monist world in the second sense (assuming the modal logic S5) then all are. Both kinds of Monism say that some categorical properties are necessarily connected to dispositions, but the first kind of Monism can be true at a world constantly with there being worlds where none of the categorical properties instantiated at that that world are so connected.

According to the first account, if there is Monist world of this kind there can be no purely Humean world which instantiates the very same properties. For if it were a Humean world, there would be no fancy lawmakers to get in the way and mask the dispositions, so the dispositions would be expressed. So, the only available patterns would be those consistent with those dispositions. And the laws would be determined by those dispositions, not by the resultant distribution or regularity facts.

If Monism of the second kind is true there is no Humean world simpliciter, since the categorical properties would necessitate dispositions, which in turn would not be masked.

We do not think that it matters which of these strains of Monism we are considering: we make the distinction just to illustrate that nothing we say depends on a kind of 'anything goes' contingentism which either (a) says all accounts of laws represent metaphysical possibilities or (b) says that there are no logical connections between the possibility of some accounts of laws, and the possibility of certain others.

Suppose, though, that necessitarianism about metaphysics is true - and metaphysically alien laws are thereby impossible. Then our account of metaphysically alien laws acts still works as a reply to the Conceivability Argument, albeit in a slightly different way. The idea is that worlds with metaphysically alien laws, though metaphysically impossible, still somehow reflect a kind of (imperfect) conceivability, and that such a conceivability plays a tacit role in fixing our intuitions. Different conceptions of the metaphysical nature of laws must be conceivable, for philosophers are divided about the metaphysical nature of laws, and for each candidate theory, there are thoughtful people - such as the ones we cite above - who believe that is how the laws are actually. To thoughtfully and sincerely take something to be actual, entails conceivability in a strong enough sense to explain an intuition.

Even this line of reply is still much more powerful than the standard reply to arguments like Langton's: that the intuition is a mere error or not widely shared. In forming the 'mental models' that drive our intuitions about other worlds, we might recombine ideas in a way partially unconstrained by our explicitly held philosophical views. The Humean intuition is generated by a model that shows actual bases and their behaviours coming apart. The input to this model-making is not a bunch of explicitly held philosophical doctrine and that is why even philosophers

${ }^{13}$ For examples of this view in areas of metaphysics outside dispositions, see Colyvan (2000); Miller (2009, 2010); Parsons (2013) and Balaguer (2014). 
who hold that metaphysically alien worlds are impossible can in this sense conceive of them. To be more precise, we might imagine a world that contains elements like those (for example) Langton or Broad says the actual world contains, even while taking the official view that such elements are impossible. And in a world like that, the metaphysically alien laws would make the behaviours different from the behaviours we would find in a world where behaviour is dictated by bases alone.

The Humean intuition, then, might be the product of the fact that everyone can form such mental models and thereby conceive of such worlds, and do so in the same way, even while some (but not all) of them take the official view that those worlds are impossible. Importantly though, it does so in a shrewd manner that accurately tracks what that model says. Thus, the Humean intuition is unlikely to be extinguished by simply holding the belief that both Monism and necessitarianism about metaphysics are true. This is why the intuition is so powerful, and why many philosophers - including both Monists and Dualists - share it.

\section{FINAL REMARKS}

Hitherto, it has been standard practice for Monists to reject the Humean modal intuition. Further, it has been assumed, only by rejecting Monism can we respect the intuition (see Langton, 1998, p. 119). If we are correct, we can respect and explain the Humean intuition while assuming Monism. Of course, as we have noted, this is not to say that by everyone's lights the intuition tells us what is possible. For the contingentist about metaphysics, it does indeed tell us what is possible, and the intuition can be taken to be veridical even when combined with Monism. For the necessitarian about metaphysics, the intuition is explained in terms of metaphysically impossible but conceivable worlds that accurately reflect certain models of laws of nature. But in neither case is one forced to deny the pervasiveness and pull of the intuition.

Finally, the idea of metaphysically alien laws may be relevant to many philosophical topics other than the Conceivability Argument we discussed. We believe that it is insufficiently discussed, however, in both the metaphysics of dispositions and other philosophical areas. While we shall not discuss those other areas here, the idea is clearly deserving of wider attention ${ }^{14}$; we hope that other philosophers will agree.

\section{ACKNOWLEDGEMENTS}

We are grateful to Michael Duncan, Toby Handfield, Kristie Miller, James Norton, Graham Oppy, an anonymous referee, and the metaphysics group at the University of Sydney for their useful feedback on the earlier versions of this article. Special thanks are due to Belinda Rickard. Andrew James Latham thanks the Ngāi Tai Ki Tāmaki Tribal Trust for their support.

\section{ORCID}

Lok-Chi Chan iD https://orcid.org/0000-0002-9777-0604

\section{REFERENCES}

Armstrong, D. (1983). What is a law of nature? Cambridge, UK: Cambridge University Press.

Balaguer, M. (2014). Anti-Metaphysicalism, necessity, and temporal ontology. Philosophy and Phenomenological Research, 89, 145-167. https://doi.org/10.1111/phpr.12129

Bird, A. (1998). Dispositions and antidotes. Philosophical Quarterly, 48,227-234.https://doi.org/10.1111/1467-9213.00098

Bird, A. (2005). Laws and essences. Ratio, 18, 437-461. https://doi.org/10.1111/j.1467-9329.2005.00304.x

Bird, A. (2007). Nature's metaphysics: Laws and properties. Oxford, UK: Oxford University Press.

\footnotetext{
${ }^{14}$ See, for example, Chan, 2018.
} 
Braddon-Mitchell, D. (2003). Qualia and analytical conditionals. Journal of Philosophy, 100, 111-135. https://doi. org/10.5840/jphil2003100321

Broad, C. D. (1923). The mind and its place in nature. London, UK: Kegan Paul.

Carroll, J. (1994). Laws of nature. Cambridge, UK: Cambridge University Press.

Chan, L. C. (2018). Emergentism and the contingent solubility of salt. Theoria, 84, 309-324. https://doi.org/10.1111/ theo.12160

Colyvan, M. (2000). Conceptual contingency and abstract existence. Philosophical Quarterly, 50, 87-91. https://doi. org/10.1111/1467-9213.00171

Dretske, F. (1977). Laws of nature. Philosophy of Science, 44, 248-268. https://doi.org/10.2307/j.ctt5vkh1c.5

Ehring, D. (1997). Causation and persistence: A theory of causation. Oxford, UK: Oxford University Press.

Heil, J. (2003). From an ontological point of view. Oxford, UK: Oxford University Press.

Huoranszki, F. (2012). Powers, dispositions, and counterfactual conditionals. Magyar Filozofiai Szemele, 56, 33-53.

Lange, M. (2004). A note on scientific essentialism, laws of nature, and counterfactual conditionals. Australasian Journal of Philosophy, 82, 227-241. https://doi.org/10.1080/713659835

Langton, R. (1998). Kantian humility: Our ignorance of things in themselves. Oxford, UK: Oxford University Press.

Langton, R. (2006). Kant's phenomena: Extrinsic or relational properties? A reply to Allais. Philosophy and Phenomenological Research, 73, 170-185. https://doi.org/10.1111/j.1933-1592.2006.tb00609.x

Lewis, D. (1986a). On the plurality of worlds. Oxford, UK: Basil Blackwell.

Lewis, D. (1986b). Philosophical papers (Vol. II). New York, NY: Oxford University Press.

Lewis, D. (2009). Ramseyan humility. In D. Braddon-Mitchell \& R. Nola (Eds.), Conceptual analysis and philosophical naturalism (pp. 203-222). Cambridge, UK: MIT Press.

MacLean, D. (2012). Review of the metaphysics of powers: Their grounding and their manifestations. Philosophy in Review, 32, 394-397.

Martin, C. B., \& Heil, J. (1999). The ontological turn. Midwest Studies in Philosophy, 23, 34-60. https://doi. org/10.1111/1475-4975.00003

Maudlin, T. (2007). The metaphysics within physics. New York, NY: Oxford University Press.

Miller, K. (2009). Defending contingentism in metaphysics. Dialectica, 63, 23-49. https://doi. org/10.1111/j.1746-8361.2009.01181.x

Miller, K. (2010). Three routes to contingentism in metaphysics. Philosophy Compass, 5, 965-977. https://doi. org/10.1111/j.1747-9991.2010.00349.x

McKitrick, J. (2010). Manifestations as effects. In A. Marmodoro (Ed.), Powers: Their grounding and their manifestations (pp. 73-83). London, UK: Routledge.

Mumford, S. (1998). Dispositions. Oxford, UK: Oxford University Press.

Oderberg, D. (2009). The non-identity of the categorical and the dispositional. Analysis, 69, 677-684. https://doi. org/10.1093/analys/anp098

Parsons, J. (2013). Conceptual conservatism and contingent composition. Inquiry, 56, 327-339. https://doi. org/10.1080/0020174x.2013.816249

Seager, W. (2009). Panpsychism. In A. Beckermann \& B. McLaughlin (Eds.), The Oxford handbook of philosophy of mind (pp. 206-219). New York, NY: Oxford University Press.

Shoemaker, S. (1980). Causality and properties. In P. van Inwagen (Ed.), Time and cause (pp. 109-135). Dordrecht, the Netherlands: Reidel.

Strawson, G. (1989). The secret connexion: Causation, realism, and David Hume. Oxford, UK: Clarendon Press.

Strawson, G. (2008). The identity of the categorical and the dispositional. Analysis, 68, 271-282. https://doi.org/10.1093/ analys/68.4.271

Swoyer, C. (1982). The nature of laws of nature. Australasian Journal of Philosophy, 60, 203-223. https://doi. org/10.1080/00048408212340641

Tooley, M. (1977). The nature of laws. Canadian Journal of Philosophy, 7, 667-698. https://doi.org/10.2307/j.ctt5vkh1c.6

Tooley, M. (1987). Causation. Oxford, UK: Clarendon Press.

Tugby, M. (2013). Platonic Dispositionalism. Mind, 122, 451-480. https://doi.org/10.1093/mind/fzt071.

Van Cleve, J. (1990). Mind - Dust or Magic? Panpsychism versus Emergence. Philosophical Perspectives, 4, $215-226$. https://doi.org/10.2307/2214193.

Yates, D. (2017). Inverse Functionalism and the Individuation of Powers. Synthese, 195, 4525-4550. https://doi. org/10.1007/s11229-017-1417-9.

How to cite this article: Chan L-C, Braddon-Mitchell D, Latham AJ. Alien worlds, alien laws, and the Humean conceivability argument. Ratio. 2020;33:1-13. https://doi.org/10.1111/rati.12248 